\title{
Health Canada e-cigarette response delayed
}

$\mathrm{H}$ ealth Canada likely won't reveal plans for regulating e-cigarettes until the fall or later, depending on when the 2015 election writ drops.

Increasing popularity of the devices - which create vapour that can be inhaled to mimic smoking and, with the right cartridge, deliver a hit of nicotine - is paralleled by concern that the devices may encourage, rather than supplant tobacco use.

On Mar. 10, the House of Commons' Standing Committee on Health issued a unanimous report calling for a new legal framework that would balance the risks of e-cigarettes with their benefits as smoking cessation tools. Key recommendations included banning e-cigarette use in public places and sales to minors, restricting advertising of the devices, and setting limits on flavouring and nicotine content of e-cigarette liquids.

Health Canada currently prohibits the sale and import of e-cigarettes that contain nicotine, treating them like unapproved drugs. But the regulator only enforces these rules (through letters to stores and seizures at the border) on the basis of complaints, and "most witnesses agreed that current regulatory efforts are not restricting access," the committee stated.

Under parliamentary rules, Federal Health Minister Rona Ambrose was supposed to respond to the report within 120 days - that is, by July 8 . But the House had already broken for the summer when that deadline passed. According to Health Canada, Ambrose

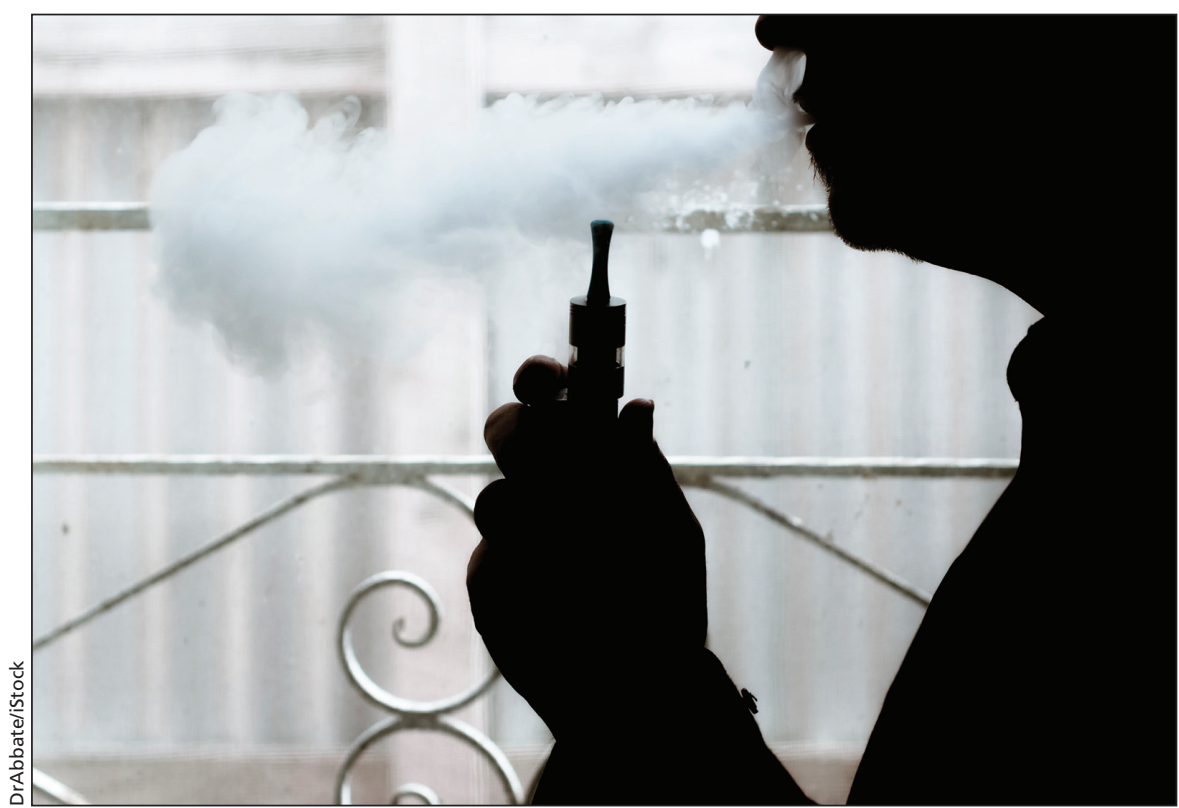

Federal action on e-cigarettes appears stalled in summer vacation, pre-election legislative torpor.

now has until Parliament resumes sitting on Sept. 21 to table a response.

More likely, the task will fall to the next government. Many expect that the Conservative government will dissolve Parliament and kick off the 2015 election campaign as early as August. As to whether Health Canada will take any new action on e-cigarettes before the October election, Senior Media Relations Advisor Maryse Durette says the regulator will respond "in due course."

In an October 2014 meeting, members of the Standing Committee on Health questioned why Health Canada was dragging its heels on e-cigarette regulation. At the time, a Health Canada representative said there was no "specific fixed end date" for concluding its policy review. New Democratic member of Parliament Matthew Kellway noted that provinces were moving more quickly. "I'm wondering how Nova Scotia gets to a unique regulatory regime but the department of health doesn't."

In the absence of federal action, most provinces have since introduced or will soon table legislation to regulate e-cigarettes more like tobacco products. For example, Ontario now bans vaping in smoke-free areas, prohibits sales to minors and restricts marketing of the devices. - Lauren Vogel, CMAJ

CMAJ 2015. DOI:10.1503/cmaj.109-5122 